\title{
ÁREA FOLIAR ATACADA PELO BICHO-MINEIRO DE UMA LAVOURA DE CAFÉ ARÁBICA, CULTIVAR OBATÃ 603
}

\author{
Eduardo Sudre Pereira ${ }^{1}$ \\ Richardson Sales Rocha ${ }^{2}$ \\ Sandy Queiroz Espinoso ${ }^{3}$ \\ Matheus Wandermurem da Silva ${ }^{4}$ \\ Jéferson Luiz Ferrari ${ }^{5}$
}

Resumo: Este estudo teve por objetivo avaliar à área foliar atacada pelo Bicho-mineiro de uma lavoura de café arábica, cultivar Obatã 603, situada no Instituto Federal do Espírito Santo Campus de Alegre. Para tanto foram realizadas amostragens de folhas retiradas dos terços superior, médio e inferior de cada planta selecionada. Foram escolhidas vinte e três plantas, totalizando sessenta e nove amostras. Essas amostras foram levadas até o Laboratório de Geoprocessamento e foram fotografadas e, em seguida, foram realizadas as seguintes medições: Área total e perímetro das folhas, e área afetada pelo ataque do Bicho-mineiro. Em média, as áreas afetadas foram de $5,6 \mathrm{~cm}^{2}$ (terço superior), $4,4 \mathrm{~cm}^{2}$ (terço médio) e 4,3 $\mathrm{cm}^{2}$ (terço inferior). O ataque pelo bicho mineiro corresponde á $17,50 \%$ no terço superior, $12,07 \%$ no terço médio e 11,35\% no terço inferior das plantas da lavoura estudada.

Palavras-chave: Coffea; Manejo de pragas e doenças; Sensoriamento remoto.

\footnotetext{
${ }^{1}$ Cafeicultura/IFES, Brasil. E-mail: eduardo-sudre@hotmail.com.

2 Cafeicultura/IFES, Brasil. E-mail: richardsonsales2016@gmail.com.

3 Cafeicultura/IFES, Brasil. E-mail: sandyespinoso@gmail.com.

${ }^{4}$ Cafeicultura/IFES, Brasil. E-mail: matheus-wandermurem@hotmail.com.

${ }^{5}$ Cafeicultura/IFES, Brasil. E-mail: ferrariluiz@gmail.com.
} 